\title{
Preface
}

\section{Cardiac replacement: total artificial heart}

This collection of work represents one of the first compilations of topics related to heart replacement with an artificial heart. A new generation of advanced heart failure specialists understand the role of the artificial heart in the management of irreversible, biventricular heart failure, and its potential to heal in the absence of an organ donor.

The concept of replacing a human heart to manage advanced, irreversible heart disease, has been percolating in scientists' minds for more than two centuries, vastly preceding the development of ventricular assist devices (VAD) and heart transplantation; however, developing the ideal human-made heart replacement has remained elusive. Pioneers such as Willem Kolff, Paul Winchell, Tetsuzo Akutsu, Denton Cooley, Domingo Liotta, Don Olsen, Robert Jarvik, William DeVries and many others developed and tested many artificial hearts. However, only one device has been used broadly enough to receive the CE mark in Europe and US Food and Drug Administration (FDA) approval for use in inpatient and outpatient settings: SynCardia Systems' (Tucson, AZ) temporary total artificial heart (t-TAH). It was this original design that was the first clinical implant, for the patient Barney Clark in 1982. As the device has evolved, so too have its indications and its name, from Symbion TAH to CardioWest TAH and, most recently, SynCardia t-TAH.

Although the Total Artificial Heart (TAH) was initially designed for use as destination therapy (DT), most of the implants worldwide have been a bridge to transplantation (BTT) in patients with Interagency Registry for Mechanically Assisted Circulatory Support (INTERMACS) profiles of 1 or 2 (i.e., those having critical cardiogenic shock or progressive decline on inotropic support, respectively). FDA and CE approval is for use as BTT in cardiac-eligible candidates at risk of imminent death from biventricular failure. Almost 2,000 t-TAHs have been implanted worldwide.

Many medical centers have acquired a vast quantity of knowledge regarding the population of patients who have undergone heart replacement, especially in the areas of correct patient selection and management. The SynCardia t-TAH will continue to evolve and improve on the technology of heart replacement. Newer concepts are currently being developed. Regardless of what the future holds with regard to TAH, heart replacement, or heart failure management, much will depend on knowledge that has been gained with the use of the t-TAH.

It is an honor and privilege to join the authors in presenting this collection of topics related to the artificial heart.

\section{Acknowledgments}

None.

Francisco A. Arabía

Departments of Surgery and Medicine, Banner UMC Phoenix, Banner-University of Arizona, Phoenix, AZ, USA.

(Email: Francisco.arabia@bannerbealth.com)

Submitted Jan 29, 2020. Accepted for publication Feb 20, 2020. doi: $10.21037 /$ acs.2020.02.05

Conflicts of Interest: Consultant to SynCardia Systems, BiVACOR TAH, CARMAT TAH, Medtronic.

View this article at: http://dx.doi.org/10.21037/acs.2020.02.05 